\title{
SINGLE CENTRE STUDY OF STONE CLEARANCE WITH URETERORENOSCOPE \& LITHOCLAST FOR URETERIC CALCULI; OUR EXPERIENCE.
}

\footnotetext{
1. MS (Urology)

Assistant Professor

Department of Urology

Nawaz Sharif Medial College Gujrat.

2. FCPS, PGR Urology

Department of Urology

Nawaz Sharif Medial College Gujrat.

3. BDS, MPH

Senior Executive Officer Research

College of Physicians and Surgeons

Pakistan.

4. MSc Statistics, BS Statistics

Senior Statistician

College of Physicians \& Surgeons

Pakistan.
}

Correspondence Address:

Dr. Qazi Adil Inam

272-B Sukh Chain Garden, Lahore.

dilurologist@gmail.com

Article received on:

07/06/2018

Accepted for publication:

08/01/2019

Received after proof reading:

$31 / 07 / 2019$

\begin{abstract}
Qazi Adil Inam, Furqan Arshad², Nabeel Naeem Baig ${ }^{3}$, Khadijah Abid ${ }^{4}$
\end{abstract}
\begin{abstract}
To decide the adequacy of ureterorenoscope by utilizing lithoclast for distal ureteric stone clearance. Study Design: Longitudinal study. Setting: Department of urology Aziz Bhatti Shaheed Teaching Hospital. Period: Feb 2014 to Dec 2016. Materials and Methods: 32 patients from medical record who underwent for stone clearance with ureteroscopy followed by lithoclast. The patients with larger upper ureteral stones were enrolled in the study though patients with stone size $<1 \mathrm{~cm}$ and co-morbidities were not included in the study. The characteristic of patients and stone, treatment modality \& outcome i.e. efficacy in terms of "successful stone clearance" were determined. Results: The average age of 32 patients was $34.28 \pm 10.11$ years. $18(56.3 \%)$ of the patients were females whereas $14(43.7 \%)$ were males. Ureteric stones were present on both right and left sides in 17 (54\%) and 15(46\%) patients. Bilateral ureteric stone was present in 2 (6.25\%) patients. The efficacy was reported as $96 \%$ for the stone size of $1-1.5 \mathrm{~cm}$ and $92 \%$ for the stone size of $1.6-3 \mathrm{~cm}$. Conclusions: We concluded that Ureterorenoscope followed by Lithoclast is the useful and safest procedure for stone clearance.
\end{abstract}

Key words: Kidneys, Lithoclast, Stone Clearance, Ureterorenoscope, Ureteric Stone Removal

Article Citation: Inam QA, Arshad F, Baig NN, Abid K. Single centre study of stone clearance with ureterorenoscope \& lithoclast for ureteric calculi; our experience. Professional Med J 2019; 26(8):1296-1299.

DOI: 10.29309/TPMJ/2019.26.08.3872

\section{INTRODUCTION}

Over the recent years progress has been observed for the surgical and therapeutic management of urolithiasis. If ureteral stones left untreated it can causes renal colic, even adverse complication may occurs such as obstructive uropathy. Expulsion of ureteral stones is very painful and causes infection or obstruction. Most of the time these stones passes spontaneously, depends upon the site and size of them. ${ }^{1-3}$ The incidence of urinary stone disease is the common urinary disease, with prevalence of $1-10 \% .{ }^{4}$

Ureteral stones may develop in kidneys and mobilized to ureter. When ureter stone expanded from $8 \mathrm{~mm}$ or more, and conservation treatments have low success rate or fail then the stones need an active manipulation for its evacuation. ${ }^{5-7}$

For the management of ureteric calculi minimal invasive techniques have been introduced. The choice of management depends on the stone's site and characteristics, preference of patient and associated cost. $^{8}$ These techniques include ureteroscopy ${ }^{9}$, extracorporeal shockwave lithotripsy (ESWL) and laparoscopic ureterolithotomy. 8,10,11 Among them ureterorenoscope ${ }^{9}$ by using Lithoclast is one of the leading management solution for the removal of ureteric stone removal.8,12,13 The objective of this research was to decide the adequacy of ureterorenoscope by utilizing lithoclast for ureteric stone clearance.

\section{MATERIAL AND METHODS}

It was a longitudinal study in which we have retrieved data of 32 patients from medical record who underwent for stone clearance with ureteroscopy using by lithoclast from Feb 2014 to Dec 2016. All the patients were dealt at Department of urology Aziz Bhatti Shaheed Teaching Hospital. The patients having larger upper ureteral stones 
were enrolled in the study though patients having stone of size less than $1 \mathrm{~cm}$ and co-morbidities were not included in the study.

All the patients were completely informed by the type of treatment techniques and its advantages \& disadvantages. All the patients were treated with Ureterorenoscope by using Lithoclast. Patient's demographics, detailed medical history, type and size of stone and postoperative outcomes were noted. Postoperative evaluation included kidney, ureter, and bladder (KUB) X-ray, ultrasound for all patients, occasionally excretory urography or non-contrast helical CT until the patient is stone free. The success of treatment were assessed by being stone free on KUB after 30 days of treatment.

The data was analyzed using SPSS ver. 20. Quantitative variables were reported as mean and standard deviation. Qualitative variables were reported as frequencies and percentages.

\section{RESULTS}

The average age of the 32 patients was noted as $34.28+10.11$ years. Eighteen $(56.3 \%)$ of the patients were females whereas $14(43.7 \%)$ were male. Among 16 patients the accessibility over stone was simple whereas it was hard to achieve success in reaching stone in two patients because of tightness of the ureter. Ureteric stones were exhibit on both right and left sides in 17 (54\%) and $15(46 \%)$ patients. Two stones were present at bilateral side, for these cases one side procedure was performed and the treatments for contralateral side were excluded from the results of this study. All the stones were observed in upper part of the ureter that lies beneath sacroiliac joint. $94 \%$ of the stone free rate was achieved by using Lithoclast. Moreover the results over ureteric stone removal and procedures were given in Table-I.

Overall $94 \%$ of the stone free rate was achieved by using Lithoclast. Moreover the results over ureteric stone removal and procedures are given in Table-II.

The complications rates over URS procedures; like intraoperative, mucosal injury, ureteral perforation, significant bleeding and ureteral stricture were ranged between $0-6 \%$ collectively.

\begin{tabular}{|c|c|c|c|}
\hline \multicolumn{2}{|c|}{ Variables } & \multicolumn{2}{|c|}{ n (\%) } \\
\hline \multicolumn{2}{|c|}{ Age $(M \pm S D)$} & \multicolumn{2}{|c|}{$34.28 \pm 10.11$} \\
\hline \multicolumn{4}{|c|}{ Gender } \\
\hline \multicolumn{2}{|c|}{ Female } & \multicolumn{2}{|c|}{$18(56.3 \%)$} \\
\hline \multicolumn{2}{|c|}{ Male } & \multicolumn{2}{|c|}{$14(43.7 \%)$} \\
\hline \multicolumn{4}{|c|}{ Ureteric Stone Location } \\
\hline \multicolumn{2}{|c|}{ Right } & \multicolumn{2}{|c|}{$17(54 \%)$} \\
\hline \multicolumn{2}{|r|}{ Left } & \multicolumn{2}{|c|}{$15(46 \%)$} \\
\hline \multicolumn{2}{|c|}{ Bilateral } & \multicolumn{2}{|c|}{$2(6.25 \%)$} \\
\hline \multicolumn{4}{|c|}{ Table-I. Baseline Data } \\
\hline $\begin{array}{l}\text { Stone Size } \\
\text { (cm) }\end{array}$ & $\begin{array}{l}\text { Number of } \\
\text { Procedures }\end{array}$ & $\begin{array}{c}\text { Median } \\
\text { Diameter }(\mathrm{cm})\end{array}$ & $\begin{array}{c}\text { Stone Free } \\
\text { Rate }\end{array}$ \\
\hline $1-1.5$ & $18(56 \%)$ & 1.4 & $96 \%$ \\
\hline $1.6-3$ & $14(46 \%)$ & 2.1 & $92 \%$ \\
\hline Total & 32 & - & $94 \%$ \\
\hline
\end{tabular}

\section{DISCUSSION}

In our study we observed $80 \%$ efficacy for initial stone free status by single procedure and $94 \%$ stone free rate for overall. We may claim an upgrading of procedures and outcomes among 6 cases of our study group. Similar findings were reported in published literature ${ }^{4,14}$, where they calculate the stone free rates as $96 \%$ \& $98 \%$ respectively. In a recent comparative study by lqbal $\mathrm{N}$ et al. showed stone- free rate after single procedure was (125/200 patients) $62.5 \%$ for ESWL and (168/200 patients) $84 \%$ for URS group $(p=0.001)$. Complications included post procedure sepsis in $3(1.5 \%)$ patient of ESWL, while 7 (3.5\%) patients of URS groups. ${ }^{15}$

The size and site of stone are independent factors of treatment failure. The urolithiasis ${ }^{16}$ guidelines claimed a $97 \%$ of stone free rates for stones size up to $1 \mathrm{~cm}$. We observed in our study that the success rate decreased with the increase of stone size. Another published review ${ }^{17}$ of data revealed that symptoms severity, diameter and location of stone were vital independent predictors of complete stone free first procedure. This has been achieved easily in female patients as compared to male patients. In another study by Kumar $\mathrm{A}$ et al. found both shockwave lithotripsy 
and semirigid ureteroscopy as safe and highly efficacious for treating patients with proximal ureteral stones $<20 \mathrm{~mm}$. For stones $<10 \mathrm{~mm}$, SWL was safer, less invasive, and of comparable efficacy with URS. For stones between 10 and $20 \mathrm{~mm}$, however, URS was more effective, with a lesser re-treatment rate. ${ }^{18}$

In our study we also reported, ureterenoscope lithotripsy as a safe and useful treatment modality. This has also been considered as safest with minimal morbidity. Similar findings were reported in literature..$^{19,20}$ The present therapy complication rate for ureteric calculi was not much high but up to $6 \%$. Another reported trial report it as $8-12 \% .{ }^{21}$ Yi-Chang $\mathrm{Li}$ et al. in their study also concluded that ureteroscopic lithotripsy is a trustworthy procedure for treating ureteral calculi of different sizes at all levels, and it can be efficaciously and safely performed in expert hands.

\section{CONCLUSION}

The present study reports outcomes and complication of ureterenoscope by using lithotripsy, comparable with different published reports. We tend to observe this procedure is the safest and useful. We tend to suggest more improvements in experience's curve and aptitudes will prompt a noteworthy progress in the achievement rate and diminished complications. Copyright@ 08 Jan, 2019.

\section{REFERENCES}

1. Sarkar BK, Chakraborty C, Sharma AR, Bae KJ, Sharma G, Doss GP, Dutta D, Ding S, Ganbold B, Nam JS, Lee SS. Novel biomarker for prostate cancer diagnosis by MRS. Front. Biosci.(Landmark Ed.). 2014 Jun $1 ; 19(7): 1186-201$.

2. Preminger G. Minimally invasive surgical techniques that significantly reduce the morbidity of stone removal are currently available. Up-To Date $\mathrm{J}$ Urol. 2012; 187:1293-7.

3. Knoll T, Alken P, Michel MS. Progress in management of ureteric stones. EAU update series. 2005; 3(1):4450.

4. Ramello A, Vitale C, Marangella M. Epidemiology of nephrolithiasis. Journal of nephrology. 2001; 13:S45-S50.
5. Mahmood A, Silbergleit A, Olson R, Cotant $M$. Urolithiasis: The influence of stone size on management. Nature Reviews Urology. 2007; 4(10):570.

6. Segura JW, Preminger GM, Assimos DG, Dretler $\mathrm{SP}$, Kahn RI, Lingeman JE, et al. Ureteral Stones Clinical Guidelines Panel summary report on the management of ureteral calculi. The Journal of urology. 1997; 158(5):1915-21.

7. Simforoosh N, Aminsharifi A, Nouralizadeh A. Difficulties in laparoscopic surgery for urinary stones. InDifficult conditions in laparoscopic urologic surgery 2018 (pp. 231-244). Springer, Cham.

8. El-Qadhi M. Outcome of ureteroscopy for the management of distal ureteric calculi: 5-years' experience. African Journal of Urology. 2015;21(1):6771.

9. Urschel JD, Vasan H. A meta-analysis of randomized controlled trials that compared neoadjuvant chemoradiation and surgery to surgery alone for resectable esophageal cancer. Am J Surg. 2003;185(6):538-43.

10. Sowter SJ, Tolley DA. The management of ureteric colic. Current opinion in urology. 2006;16(2):71-6.

11. Borofsky MS, Lingeman JE. The role of open and laparoscopic stone surgery in the modern era of endourology. Nature Reviews Urology. 2015;12:392.

12. Denstedt JD, Eberwein PM, Singh RR. The Swiss Lithoclast: a new device for intracorporeal lithotripsy. The Journal of urology. 1992;148(3):1088-90.

13. Matsuoka K, lida S, Nakanami M, Koga H, Shimada A, Mihara T, et al. Holmium: yttrium-aluminumgarnet laser for endoscopic lithotripsy. Urology. 1995;45(6):947-52.

14. Matlaga BR, Jansen JP, Meckley LM, Byrne TW, Lingeman JE. Treatment of ureteral and renal stones: a systematic review and meta-analysis of randomized, controlled trials. The Journal of urology. 2012;188(1):130-7.

15. Iqbal N, Malik Y, Nadeem U, Khalid M, Pirzada A, Majeed $M$, et al. Comparison of ureteroscopic pneumatic lithotripsy and extracorporeal shock wave lithotripsy for the management of proximal ureteral stones: A single center experience. Turkish journal of urology. 2018;44(3):221-7.

16. Mugiya S. Guidelines on urolithiasis: Update of diagnosis and treatment. Hinyokika kiyo Acta urologica Japonica. 2012;58(12):703-6. 
17. Kurahashi T, Miyake H, Oka N, Shinozaki M, Takenaka A, Hara I, et al. Clinical outcome of ureteroscopic lithotripsy for 2,129 patients with ureteral stones. Urological research. 2007;35(3):149-53.

18. Kumar A, Nanda B, Kumar N, Kumar R, Vasudeva P, Mohanty NK. A prospective randomized comparison between shockwave lithotripsy and semirigid ureteroscopy for upper ureteral stones <2 cm: A single center experience. J Endourol. 2015;29(1):4751.
19. Rana AM, Aquil S, Khawaja AM. Semirigid ureteroscopy and pneumatic lithotripsy as definitive management of obstructive ureteral calculi during pregnancy. Urology. 2009;73(5):964-7.

20. Hong YK, Park DS. Ureteroscopic lithotripsy using Swiss Lithoclast for treatment of ureteral calculi: 12-years experience. Journal of Korean medical science. 2009;24(4):690-4.

21. Cevik I, Dillioglugil O, Akdas A, Siegel Y. Is stent placement necessary after uncomplicated ureteroscopy for removal of impacted ureteral stones? Journal of endourology. 2010;24(8):1263-7.

\begin{tabular}{|c|c|c|c|}
\hline \multicolumn{2}{|c|}{ AUTHORSHIP AND CONTRIBUTION DECLARATION } \\
\hline Sr. \# & Author-s Full Name & \multicolumn{1}{|c|}{ Contribution to the paper } & Author=s Signature \\
\hline 1 & Qazi Adil Inam & $\begin{array}{l}\text { Conception \& design of study, } \\
\text { Developed the methodology. } \\
\text { Data collection, Literature } \\
\text { search. }\end{array}$ \\
\hline 2 & Furqan Arshad & $\begin{array}{l}\text { Review it critically for important } \\
\text { intellectual content and made the } \\
\text { final changes. } \\
\text { Analysis is interpretation of data, } \\
\text { wrote the manuscript. }\end{array}$ \\
\hline 4 & Khadijah Abid & & \\
\hline
\end{tabular}

